\title{
ESTUDO COMPARATIVO DA RESISTÊNCIA À COMPRESSÃO DE BLOCOS DE CONCRETO PRODUZIDOS COM DIFERENTES CIMENTOS E DOSADOS EM AMBIENTE DE FÁBRICA
}

\author{
Comparative study of the concrete blocks compression strength \\ produced with different cements and dosing in factory environment
}

\author{
Stael Amaral Padilha ${ }^{1}$, Charlei Marcelo Paliga ${ }^{2}$, Ariela da Silva Torres ${ }^{3}$
}

Recebido em 18 de abril de 2017; recebido para revisão em 23 de abril de 2017; aceito em 08 de maio de 2017; disponível on-line em 16 de maio de 2017.

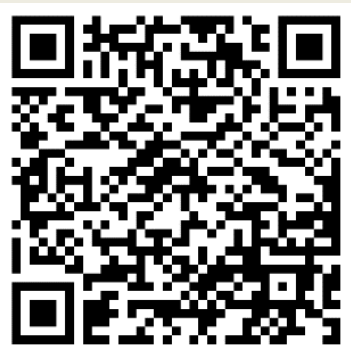

PALAVRAS CHAVE:

Bloco estrutural;

Dosagem de concreto;

Tecnologia da arquitetura; Resistência à compressão; Modelagem em fábrica.

\section{KEYWORDS:}

Structural block; Concrete dosage; Architecture technology; Compressive strength; Factory molding.

* Contato com os autores:

${ }^{1}$ e-mail: staelpadilha@hotmail.com (S. A. Padilha)

Engenheiro Civil, mestrando em Arquitetura e Urbanismo pela Universidade Federal de Pelotas.

22e-mail: charlei.paliga@ufpel.edu.br (C.M. Paliga)

Eng. Civil, Doutor, Professor, Faculdade de Arquitetura e Urbanismo/Departamento de Tecnologia da Construção, Universidade Federal de Pelotas.

${ }^{3}$ e-mail: arielatorres@gmail.com (A. S. Torres )

Eng. Civil, Doutor, Professor, Faculdade de Arquitetura e Urbanismo/Departamento de Tecnologia da Construção, Universidade Federal de Pelotas.

\begin{abstract}
RESUMO: De acordo com Frasson Junior (2000), cada tipo de concreto possui características bem próprias, mas podem ser classificados dentro de dois grandes grupos: plásticos e secos. As diferenças entre eles fazem com que as metodologias de dosagem sejam também distintas. concretos plásticos, por serem os mais utilizados possuem metodologias consolidadas e uma determinação da resistencia do material com uma boa confiança, diferentemente do concreto seco, que ainda possui diversos estudos de métodos de sagem, e até adaptações das metodologias dos concretos plásticos para o uso neste tipo dosagem proposta por Frasson Junior (2000), realizada em ambiente de fábrica, estudando 作 e CPV ARI, e três relações cimento:agregado (1:6, 1:8 e 1:10). O parâmetro de avaliação do comportamento dos blocos foi através da análise dimensional e resistência à compressão, seguindo as recomendações de ensaio da NBR 12118 (ABNT, 2014). Os resultados excluíram poucos blocos no ensaio de análise dimensional e demonstraram que todas as famílias apresentaram resistência mecânica compatíveis com elementos a serem usados estruturalmente, e que há bastante variação no consumo de cimento entre traços.
\end{abstract}

ABSTRACT: According to Frasson Junior (2000), each concrete type has its own characteristics, but can be classified into two large groups: plastic and dry. The differences between them make dosing methodologies different. The most commonly used plastic concretes have with a good confidence, unlike dry concrete, which still has several studies of dosing methods, and even adaptations of the methodologies of plastics concretes for The use in this type of Frasson Junior (2000), carried out in a factory environment, studying three types of cements for the production of dry concrete blocks: CPII-F 32, CPIV 32 and CPV ARI, and three cement: ratios (1: 6, 1: 8 and 1:10). The parameter of evaluation of the behavior of the blocks was through the dimensional analysis and resistance to compression, following the recommendations of test of NBR 12118 (ABNT, 2014). The results excluded a few blocks in the 列 compatible with elements to be used structurally, and that there is enough variation in the consumption of cement between traces. 


\section{INTRODUÇÃO}

Segundo Hendry (2002), mundialmente falando, a alvenaria estrutural passou a ser tratada como uma tecnologia de construção civil por volta do século XVII quando os princípios da estática foram aplicados para a investigação da estabilidade de arcos e domos. Entre os séculos XIX e XX, edifícios em alvenaria estrutural foram construídos com espessuras excessivas de paredes, como por exemplo o edifício Monadnock45 em Chicago, que se tornou um símbolo da moderna alvenaria estrutural (RAMALHO e CORRÊA, 2003). Entretanto, a perda de espaço e baixa velocidade de construção evidenciaram a pequena aceitação de edifícios altos em alvenaria portante na época frente à emergente alternativa de estruturas de concreto armado. Assim, os edifícios em alvenaria estrutural tiveram pouca aplicação durante um período de 50 anos.

A partir dos anos 20 iniciaram-se pesquisas e desenvolvimento na área de materiais e cálculos com utilização de alvenarias com função estrutural. Segundo Prudêncio Júnior (1986), na Índia, em 1923, testes extensivos sobre a alvenaria foram executados e resultaram numa teoria racional de projeto sendo considerado o verdadeiro início da alvenaria armada. Em 1948, na Inglaterra, foi elaborada a primeira norma consistente para o cálculo da alvenaria de tijolos. MEDEIROS, 1993 relata que em 1951 um edifício em alvenaria foi calculado racionalmente na Suíça e construído em alvenaria não armada, o que representou um marco importante para alvenaria estrutural. Em 1967 surgiram, nos Estados Unidos, as especificações do NCMA ("Specification for the design and the construction of Load-Bearing Concrete Masonry"), resultado de anos de pesquisa na área e foram rapidamente adotadas em todo o território norteamericano, permitindo várias construções em alvenaria estrutural.

No Brasil, a alvenaria estrutural é utilizada desde o início do século XVII. Entretanto, a alvenaria com blocos estruturais, encarada como um processo construtivo voltado para a obtenção de edifícios mais econômicos e racionais demorou muito a encontrar seu espaço (RAMALHO e
CORRÊA, 2003). O início nacional foi, mesmo, com a importação pela Construtora Camargo Corrêa, em 1952, da primeira máquina de produção mecânica, em escala industrial. Inicialmente, a fabricação de blocos tinha o intuito de resolver o problema da grande quantidade de pó de pedra gerada pela pedreira Reago. No ano de 1966, tem início a produção de blocos de concreto com alta resistência (ALY, 1992).

Os blocos de concreto pré-moldado para alvenaria estrutural têm como princípio básico proporcionar a facilidade construtiva no emprego de um único elemento, proporcionando uma técnica de execução simplificada, menor diversidade de materiais empregados no canteiro de obras, redução do número de especializações da mão de obra empregada e redução de interferências, entre os subsis-temas.

Em função dos blocos estruturais possuírem distinto método de dosagem, vem sendo necessário diversos estudos que procuram atingir um material de excelência em qualidade e também econômico. Pensando nestes quesitos, este trabalho se voltou a estudar a dosagem dos materiais locais para fabricação de blocos estruturais de concreto do tipo "seco".

\section{OBJETIVO}

Este trabalho tem como objetivo realizar um estudo sobre o uso da dosagem proposta por Frasson Junior (2000), realizada em ambiente de fábrica, estudando três tipos de cimentos: CPII-F 32, CPIV 32 e CPV ARI, a fim de atingir resultados satisfatórios de ordem econômica e sustentável, além de avaliar o desempenho deste produto, observando as propriedades e requisitos exigidos pela norma NBR 6136 (ABNT, 2014): resistência à compressão simples e análise dimensional, a partir dos ensaios estabelecidos na NBR 12118 (ABNT, 2014).

\section{REVISÃO BIBLIOGRÁFICA}

Os estudos baseados no tema alvenaria estrutural no Brasil têm seu ponto forte em 
desenvolvimento de padrões de projeto e execução, como é o caso de Zechmeinster (2005) que apresentou uma proposta de padronização de dimensões de unidades de blocos, comparando modelos brasileiros e alemães. Neste mesmo padrão de estudos pode-se citar ainda: Baldauf (2004), Roman et al (2004), Medeiros (1993) e Franco (1992).

Algumas pesquisas que abordaram 0 material componente dos blocos estruturais foram: Barbosa (2004) que estudou o efeito na deformação em blocos com diferentes concretos, Medeiros et al. (1994) e Ferreira Junior (1995) analisaram a interferência do processo de produção na qualidade dos blocos. Já Soto Izquierdo (2011) avaliou a incorporação de fibra natural de sisal no concreto para bloco estrutural.

A partir daí, os pesquisadores se depararam com a grande dificuldade de métodos de dosagens para concretos de blocos estruturais, tudo isso em função da grande diferença do material, e desta maneira da impossibilidade de moldar corpos de prova em ambiente de laboratório. A partir deste raciocínio, alguns estudos foram desenvolvidos com o objetivo de proporcionar técnicas de dosagem para este tipo de concreto. Os principais são: Prudêncio Júnior et al. (2000), Frasson Junior (2000), Rodrigues (1995) e Tango (1984).

De acordo com Frasson (2000), cada tipo de concreto possui características bem próprias e diversificadas, mas podem ser classificados dentro de dois grandes grupos: os concretos plásticos e os concretos "secos", de acordo com seu comportamento que permite definir propriedades como resistência à compressão, entre outras. Existem várias diferenças entres estes dois grupos de concreto. Entre elas, pode-se destacar a forma com que o ar é aprisionado às misturas, a trabalhabilidade e o abatimento, a granulometria final, a relação água/materiais secos, os processos de produção, entre outras. Estas diferenças fazem com que as metodologias de dosagem sejam também distintas, e o que vale para os concretos plásticos nem sempre pode ser utilizado como regra para os concretos "secos".

Os concretos plásticos, por serem os mais utilizados e pela facilidade com que podem ser moldados para estudos em laboratório, possuem metodologias de dosagem consolidadas e que proporcionam uma determinação da resistência do material com uma boa confiança. Podemos citar as seguintes metodologias: ABCP, IPT, IME, INT, IPERS, TUTIKAN, entre outros.

Para os concretos "secos" empregados na produção de blocos estruturais, as metodologias já consolidadas para concretos plásticos desenvolveram técnicas para a diferença entre os materiais. Frasson et al. (2008) descreveram os principais métodos de dosagem de concreto para blocos estruturais, porém demonstraram inúmeras dificuldades, entre elas: Método de dosagem Besser Company, Método de dosagem da ABCP, Método de dosagem do IPT/Epusp e Método de dosagem da Columbia. Todos estes métodos demandam testes excessivos já na própria máquina vibro-prensa. Além disso, a maioria dos ensaios não leva em consideração peculiaridades e características inerentes ao processo de produção dos blocos de concreto, que deve ocorrer em ambiente de fábrica. Pensando nisto, Frasson (2000) desenvolveu uma metodologia de dosagem que visa à redução de testes em escala real de produção, tornando o estudo de dosagem uma tarefa mais ágil e econômica, e que leva em conta parâmetros importantes do processo produtivo, desconsiderados nos demais métodos. 0 estudo obteve resultados satisfatórios na previsão das resistências mecânicas dos blocos de concreto a partir de estudos laboratoriais em corpos-de-prova cilíndricos $5 \times 10 \mathrm{~cm}$ e também comprovou a importância do controle das variáveis em um processo produtivo em ambiente de fábrica. $\mathrm{O}$ autor sugere que a metodologia seja testada em diferentes situações para que possa ser comprovada sua eficiência na previsão das resistências e outras características (textura e coesão) dos blocos produzidos em diferentes fábricas e com diferente agregados. A metodologia de Frasson (2000) tem sido utilizada em diversas pesquisas que tem o bloco estrutural como tema, principalmente nas que foram desenvolvidas em ambiente de fábrica. 


\subsection{PARÂMETROS DE AVALIAÇÃO PARA BLOCOS ESTRUTURAIS}

As avaliações dos blocos produzidos devem ser realizadas com base nos requisitos estabelecidos na NBR 6136 (ABNT, 2014) e os parâmetros de ensaios na NBR 12118 (ABNT, 2014). A classificação dos blocos de concreto da NBR 6136 (ABNT, 1994) tratava apenas dos blocos estruturais, e os dividia em classes de acordo com a resistência característica à compressão do bloco (fbk): $A$ (fbk $\geq$ 6,0 MPa) e B (fbk $\geq 4,5 \mathrm{MPa}$ ). Em 2006, a execução de edificações em alvenaria estrutural, respeitando as normas técnicas, teria que usar, pelo menos, blocos da classe $B$ - peças mais pesadas e maiores, com, no mínimo, $14 \mathrm{~cm}$ de largura. Após a revisão de 2006, a classe $C$ ( fbk $\geq 3,0 \mathrm{MPa}$ ), que regulamenta os novos blocos foi acrescentada na classificação. Ela permitia blocos estruturais com paredes longitudinais e transversais mais finas, de $18 \mathrm{~mm}$, e que blocos de $9 \mathrm{~cm}$ de largura poderiam ser usados na construção de imóveis de um pavimento, e blocos de $11,5 \mathrm{~cm}$ de largura em edificações de dois pavimentos. Para construções maiores, deveriam ser utilizados os blocos de $14 \mathrm{~cm}$ e $19 \mathrm{~cm}$ de largura. Além da classe $\mathrm{C}$, foi adicionado ao texto da norma a classe $D$ (fbk $\geq 2,0 \mathrm{MPa}$ ), com as especificações para blocos de concreto de vedação (sem função estrutural). No momento, a norma foi novamente atualizada. A NBR 6136 (ABNT, 2014) alterou a classificação dos blocos, omitindo a classe $D$ e alterando os valores de resistência característica à compressão axial. Os novos valores estão descritos no Quadro 1.

Além das alterações já apresentadas no Quadro 1, a NBR 6136 (ABNT, 2014) estabeleceu: que obras abaixo do nível do solo devem ser utilizados, obrigatoriamente, blocos classe A. Os blocos classe $\mathrm{C}$ com função estrutural poderão ter largura de $90 \mathrm{~mm}$ para edificações de no máximo um pavimento, para blocos com largura de $115 \mathrm{~mm}$ edificações de no máximo dois pavimentos e as larguras de 140 e $190 \mathrm{~mm}$ para edificações de até 5 pavimentos. Além disso, a largura de $65 \mathrm{~mm}$ tem seu uso restrito à alvenaria sem função estrutural.

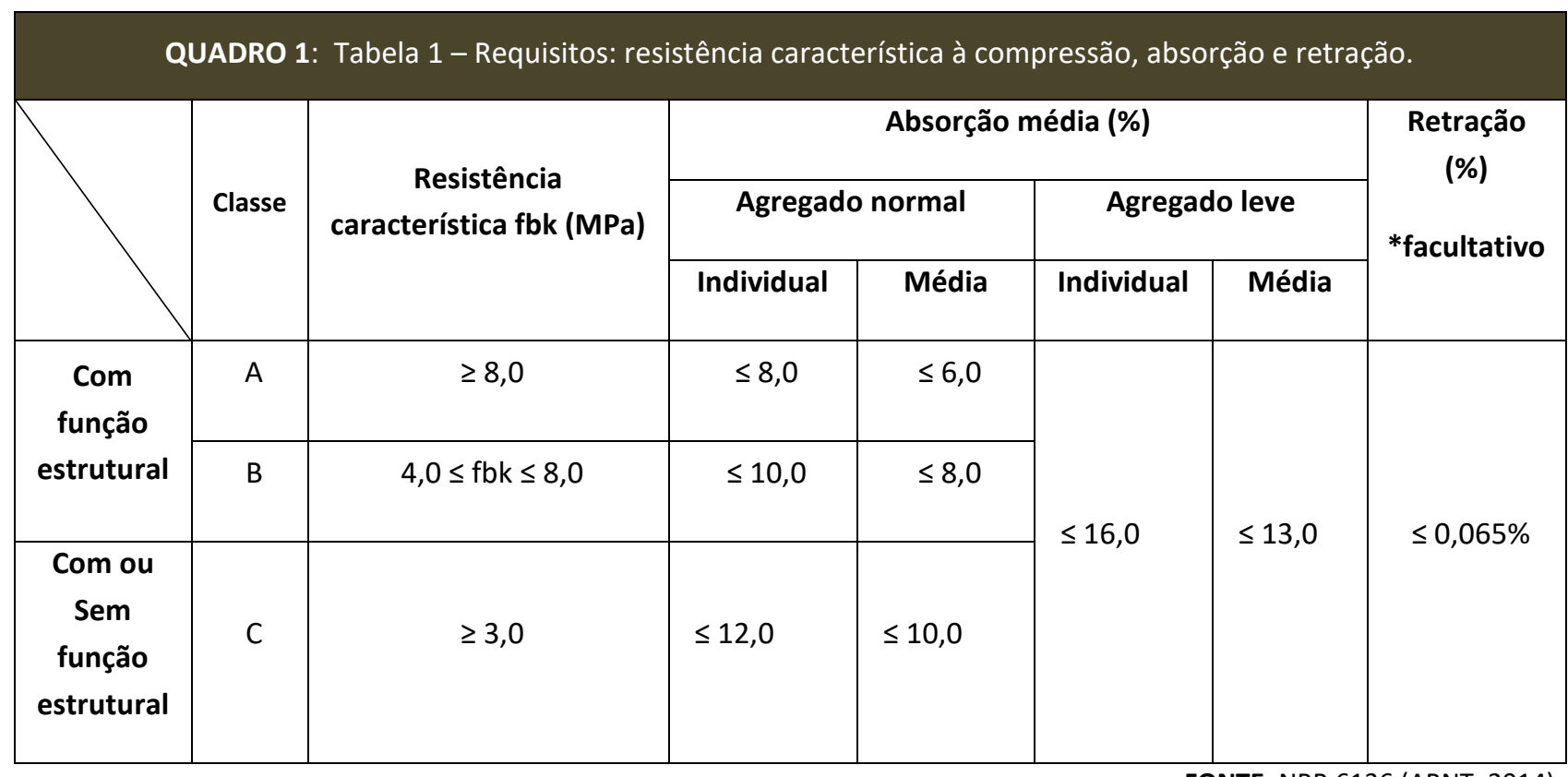




\section{METODOLOGIA}

Como já descrito anteriormente, o método de dosagem de Frasson (2000) e de Prudêncio Júnior et al. (2000) estabelece que para entender o comportamento de materiais para concretos secos, deve-se utilizar diversas famílias de traços que se diferenciem no quantitativo de agregados. Sendo sugerido que o processo tenha famílias entre 1:6 (cimento : agregados) a $1: 13$ (cimento : agregados).

Para esta pesquisa optou-se por utilizar as famílias 1:6, 1:8 e 1:10. Esta escolha foi baseada em ter famílias com maior e menor consumo de cimento, mas com blocos possuindo bom aspecto de coesão. Como foram utilizados três tipos de cimentos (CPIIF 32, CPIV 32, CPV ARI), para três famílias de traços, resultou um total de 9 famílias para este estudo (CPII 1:6; CPII 1:8; CPII 1:10; CPIV 1:6; CPIV 1:8; CPIV 1:10; CPV 1:6; CPV 1:8; CPV 1:10). Os traços unitários - cimento : agregados utilizados para cada família estão apresentados na Tabela 1.

\subsection{MATERIAIS UTILIZADOS}

Os materiais utilizados na fabricação dos blocos estruturais são os componentes do concreto : cimento, areias (geralmente com duas composições granulométricas diferentes), brita, água e aditivo, conforme Tabela 2.

\begin{tabular}{ccccccc}
\hline \multicolumn{5}{c}{ TABELA 1: } & \multicolumn{5}{c}{ Traços unitários utilizados na produção em fábrica. } \\
\hline Família & $\begin{array}{c}\text { Ciment } \\
\text { o }\end{array}$ & Areia média & Areia fina & Brita & Aditivo \\
\hline $1: 6$ & 1 & 3,9 & 1,2 & 0,9 & 0,1 \\
\hline $1: 8$ & 1 & 5,2 & 1,6 & 1,2 & 0,1 \\
\hline $1: 10$ & 1 & 6,5 & 2 & 1,5 & 0,1 \\
\hline
\end{tabular}

TABELA 2: Materiais utilizados para fabricação dos blocos estruturais.

\begin{tabular}{|c|c|c|}
\hline & Tipo & Justificativa de uso \\
\hline \multirow{3}{*}{ Cimento } & CPII F 32 & $\begin{array}{c}\text { Por ser um material de composição química com poucas adições } \\
\text { minerais e o tempo de pega do material não é acelerado. }\end{array}$ \\
\hline & CPIV-32 & Por ser o material de maior uso na região sul do país \\
\hline & CPV-ARI & $\begin{array}{l}\text { Por apresentar o menor teor de adições em sua composição, por } \\
\text { obter as características físicas desejáveis (hidratação e resistência } \\
\text { à compressão inicial), ser de fácil obtenção e muito utilizado nas } \\
\text { indústrias de pré-moldados. }\end{array}$ \\
\hline Água & Abastecimento local & Por ser material ofertado \\
\hline \multirow{2}{*}{$\begin{array}{l}\text { Agregado } \\
\text { miúdo }\end{array}$} & Areia fina & $\begin{array}{l}\text { Tem a capacidade de proporcionar coesão à mistura e ser } \\
\text { adquirida em mercado regional }\end{array}$ \\
\hline & Areia média & Proporcionar volume e ser adquirida em mercado regional \\
\hline
\end{tabular}

\begin{tabular}{ccc}
\hline $\begin{array}{c}\text { Agregado } \\
\text { graúdo }\end{array}$ & Brita de origem basáltica & Ser adquirida em mercado regional \\
\hline Aditivo & Plastificante & $\begin{array}{c}\text { Para dar melhor plasticidade ao concreto, por ser um concreto } \\
\text { seco, e também por melhor aglutinação do concreto, facilitando } \\
\text { a moldagem e desmoldagem dos elementos pré-fabricados. }\end{array}$ \\
\hline
\end{tabular}




\subsection{MOLDAGEM DOS BLOCOS}

A moldagem dos blocos em ambiente de fábrica foi realizada a partir das seguintes etapas:

(1) Armazenamento dos materiais: o cimento foi armazenado em silo e os agregados em baias cobertas;

(2) Pesagem dos agregados e verificação da umidade através de sensores, possibilitando $\mathrm{o}$ ajuste dos traços $\mathrm{e}$ determinação da quantidade de água;

(3) O transporte do cimento aconteceu por rosca helicoidal do silo de armazenamento até a balança de pesagem, que está posicionada sob o misturador. Após a verificação da massa, o material é liberado para o interior do misturador;

(4) O aditivo foi armazenado em reservatório inferior, sendo bombeado para o reservatório superior, onde foi verificada a quantidade necessária e posteriormente liberado para a mistura em sistema de aspersão. Desta maneira certificou-se a distribuição homogênea na mistura;

(5) A água foi armazenada em outro reservatório inferior, bombeada a outro reservatório superior, onde o seu controle de vazão é determinado em conjunto ao funcionamento do sensor de umidade (este posicionado no interior do misturador). 0 sistema determinou leituras a cada 3 segundos que controlaram a umidade ideal e a válvula de liberação de água;

(6) Mistura dos materiais até ter uma massa homogênea;

(7) Transporte do concreto do misturador para a máquina de moldagem por meio de vagonete movimentado sobre trilhos;

(8) Liberação do concreto do vagonete para o silo de armazenamento da vibro prensa;

(9) Moldagem dos blocos: primeiro com abertura do silo; após com preenchimento da forma; seguido do acionamento de vibradores para acomodação do material na forma e processo de prensagem do material. A prensa e o molde foram liberados e o material já moldado é conduzido a esteira extratora;

(10)Sistema extrator: após o término do ciclo (descrito no item anterior) foi feita a primeira avaliação visual dos blocos (Figura 1), descartando os que apresentavam defeitos como fissuras ou rebarbas. A verificação da precisão dimensional foi feita por uma escova em rolo, que retirava as rebarbas superiores. Posteriormente os blocos foram conduzidos a sistemas de elevadores (Figura 2);

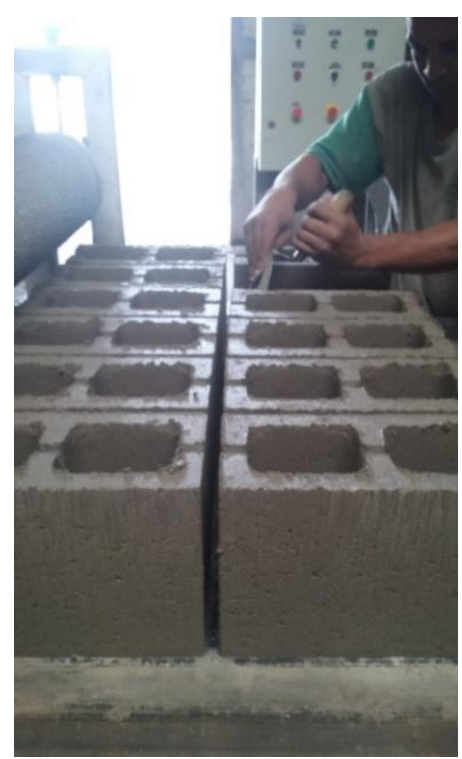

FIGURA 1: primeira avaliação visual dos blocos FONTE: Autoria Própria.

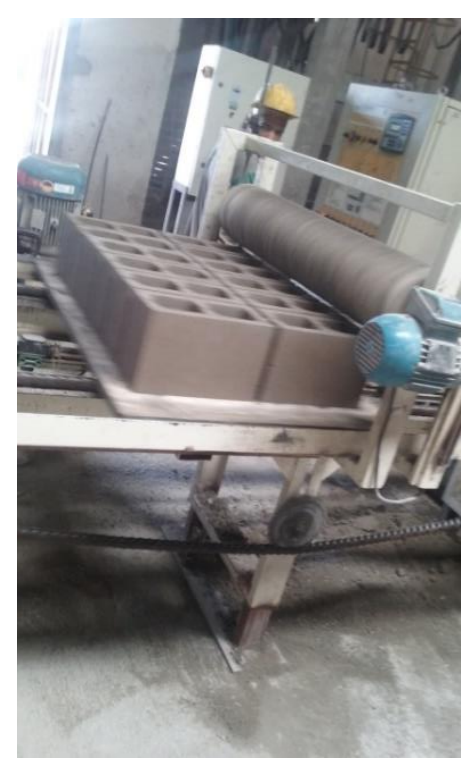

FIGURA 2: blocos passando pela escova em rolo FONTE: Autoria Própria. 
(11)Cura: após retirar os blocos do sistema de elevadores, as peças foram movimentadas por meio de empilhadeiras para as prateleiras, as quais permanecem até o dia seguinte, em ambiente protegido de intempéries;

(12)Paletização: Após 24h, as prateleiras com os blocos foram transportadas por empilhadeiras até os elevadores de paletização, nos quais foram conduzidos a esteira extratora, onde a paletizadora pneumática retirou os blocos das tábuas e os armazenou nos paletes. Para finalizar o processo, os paletes (com 96 blocos) foram protegidos por filme plástico e amarrados com fita plástica;

(13)Estoque e cura final.

\subsection{CAPEAMENTO DOS BLOCOS}

Os blocos, ao atingirem as idades determinadas para os ensaios de caracterização foram transportados para o laboratório, onde foram capeados para posterior realização do ensaio de resistência à compressão. 0 material escolhido para capeamento dos blocos interfere diretamente nos resultados do ensaio de resistência à compressão. 0 material que menos interfere nos resultados é o enxofre, porém pelo seu efeito ambiental e pelo risco a saúde dos que manuseiam o material não é mais recomendada sua utilização (FERNANDES, 2015). Diversos estudos já foram realizados com diferentes sistemas de capeamento (IZQUERDO, 2011; BEZERRA, 2007; OSAMA e AMEED, 2003; MAURICIO et al., 2004; FORTES, 2012; DRYSDALE et al.,2012), e os resultados demonstraram que os materiais com menores distorções de resultados e com maiores valores de resistência foram o enxofre e o gesso. Este trabalho optou por utilizar o capeamento em gesso, justificado nas afirmações anteriores e também em Fernandes (2015).

O processo de capeamento segue algumas etapas: primeiro é necessário a mistura do pó de gesso com água; após o material é espalhado sobre uma mesa de vidro e os blocos apoiados sobre este material. Transcorridos no mínimo 40 minutos, os blocos são retirados e o processo repetido do lado contrário ao já capeado. Ao final do processo, ambos os lados que possuem as aberturas no bloco estão capeados, conforme Figura 3. Nesta pesquisa o processo de capeamento foi realizado 24 horas antes do ensaio de resistência à compressão e após a análise dimensional dos blocos.

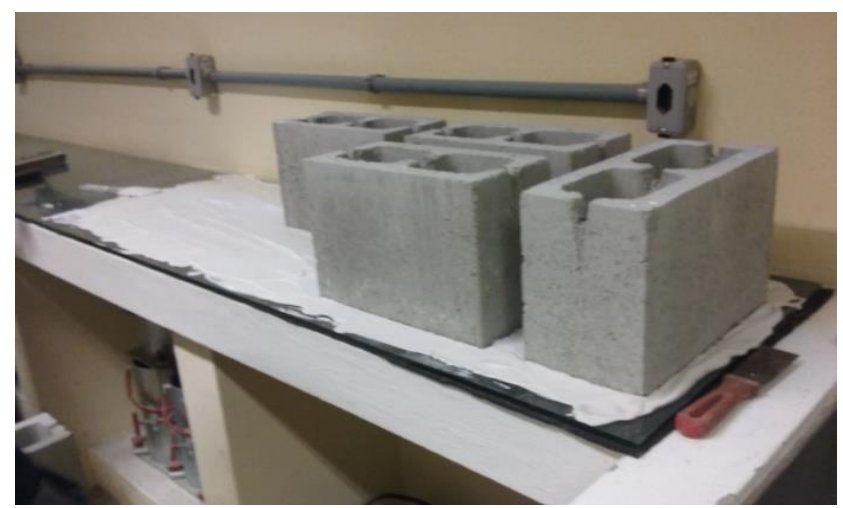

Figura 3: Capeamento com gesso. FONTE: Autoria Própria

\subsection{PARÂMETROS AVALIADOS}

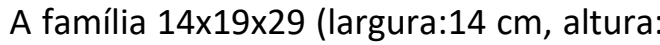
$19 \mathrm{~cm}$, comprimento: $29 \mathrm{~cm}$ ) escolhida para este estudo foi definida em função de ser a família produzida pela empresa, no qual foram desenvolvidos os traços. Além de possuir uma modulação que facilita o uso em projetos arquitetônico e pode ser utilizado em paredes externas e internas.

Nesta pesquisa foi definida a avaliação de dois parâmetros da NBR 6136 (ABNT, 2014): análise dimensional e resistência à compressão.

A análise dimensional foi realizada conforme procedimento descrito na NBR 12118 (ABNT, 2014) que determina que a resolução deve ser de $1 \mathrm{~mm}$ nas dimensões da peça: largura, comprimento, altura e espessura de paredes. Para cada dimensão foram realizadas três leituras em pontos distintos, sempre pelo fundo do bloco (onde tem a maior espessura), na idade de 28 dias. Após, realizou-se uma média simples entre as medidas de cada ponto e comparou-se com as dimensões padrão da família de bloco utilizada nesta pesquisa. A tolerância permitida, de acordo com a NBR 6136 (ABNT, 2014), em termos das dimensões são: \pm 2 $\mathrm{mm}$ para largura; $\pm 3 \mathrm{~mm}$ para altura e comprimento e a espessura mínima de qualquer parede tem 
tolerância de - $1 \mathrm{~mm}$.

Para acompanhar a evolução de resistência à compressão, os blocos foram ensaiados nas idades de 7 e 28 dias. Sendo 3 blocos para cada família aos 7 dias, e 6 blocos para cada família aos 28 dias. O ensaio foi realizado, no laboratório da engenharia civil da UFPel, conforme procedimento descrito na NBR 12118 (ABNT, 2014), que estipula que a tensão aplicada na área bruta do bloco ocorra sem choques, numa taxa de 0,05 \pm 0,01 $\mathrm{MPa} / \mathrm{s}$ (quando fbk < $8 \mathrm{MPa}$ ). Ressalta-se que para resistências superiores ou iguais a $8 \mathrm{MPa}$ poderia ser utilizado $(0,15 \pm 0,03) \mathrm{MPa} / \mathrm{s}$. Optou-se, nesta pesquisa, pelo primeiro $(0,05 \pm 0,01 \mathrm{MPa} / \mathrm{s})$ valor de tensão informado por não se ter conhecimento dos valores que seriam obtidos nos resultados. O cálculo da tensão no bloco é determinado com a área de aplicação cheia, ou seja, utilizando 29×14 cm.

A NBR 6136 (ABNT, 2014) indica que apenas tem validade o ensaio realizado aos 28 dias, e deve ser com uma amostra mínima de 6 blocos. 0 cálculo da resistência característica do lote deve ser feito pela Equação 1:

$$
f b k=[f b(1)+f b(2)]-f b(3) \quad \text { Eq. [1] }
$$

\section{Em que:}

fbk = resistência característica da amostra (MPa); $\mathrm{fb}(\mathbf{1}), \mathrm{fb}(\mathbf{2}), \mathrm{fb}(\mathbf{3})$ = são os valores de resistência à compressão individuais dos corpos de prova ordenados crescentemente.

A condição determinada pela norma para que o resultado seja aceitável é que $\mathrm{fbk} \geq 0,89 * \mathrm{fb}(1)$.

Para análise deste trabalho foi realizada, também, a média simples dos valores da amostra de cada família para cada idade, com o objetivo de acompanhar a evolução de resistência à compressão. Ressalta-se que os valores dos blocos não aprovados no requisito análise dimensional foram retirados deste cálculo de média simples. Foi, também, utilizado o parâmetro de cálculo indicado pela NBR 6136 (ABNT, 2014), descrito acima. Novamente, os valores dos blocos não aprovados no requisito análise dimensional foram retirados desta avaliação proposta pela norma.

\section{RESULTADOS E DISCUSSÕES}

\subsection{RESULTADOS DA ANÁLISE DIMENCIONAL}

Conforme o procedimento descrito na NBR 12118 (ABNT, 2014), para cada dimensão foram realizadas três leituras em pontos distintos. Após, realizou-se uma média entre as medidas de cada ponto e comparou-se com as tolerâncias admitidas.

Para o cimento CPII F 32 foi possível verificar que: o bloco 2 da família CPII 1:6 (186,8 $\mathrm{mm}$ ) e o bloco 1 da família CPII 1:10 (181,0 mm) foram reprovados no quesito altura, portanto descartado do lote de avaliação. Já para o cimento CPIV 32 o bloco 6 da família CPIV 1:6 e o bloco 4 da CPIV 1:8 foram excluídos na análise. O primeiro bloco ultrapassou o limite máximo $(193,8 \mathrm{~mm})$ e o segundo bloco ultrapassou o limite inferior $(186,5$ $\mathrm{mm})$. Nos resultados do CPV ARI todos os blocos foram aprovados para continuarem sendo avaliados. Concluída a etapa de análise dimensional, os blocos foram submetidos ao ensaio de resistência à compressão.

\subsection{RESULTADO DA RESISTÊNCIA À COMPRESSÃO}

Os resultados médios do ensaio de resistência à compressão das famílias moldadas em ambiente de fábrica estão apresentados na Figura 4.

Os resultados demonstraram que em todos os tipos de cimentos as famílias 1:10 foram as que apresentaram menores valores de resistência à compressão para as idades de 7 e 28 dias.

Ao analisar-se os resultados das famílias do cimento CPII F 32 nota-se que a família 1:8 foi a que teve maior ganho de resistência entre o procedimento realizado aos 7 dias e aos 28 dias, com aumento de aproximadamente $20 \%$. Também, é possível notar que com este ganho o valor de resistência se aproximou da família 1:6. Ao avaliarse os resultados de 28 dias, verifica-se que da família 1:6 para 1:8 houve um decréscimo de $8,09 \%$ - ou $0,81 \mathrm{MPa}$ - no valor da resistência, enquanto que da família $1: 6$ para $1: 10$ a redução foi de $37,35 \%$. As famílias 1:6 e 1:10 apresentaram resultados aos 28 dias inferiores aos 7 dias. Acredita-se que seja porque ambas as famílias tiveram blocos excluídos na análise dimensional (aos 28 dias), reduzindo a amostra. 


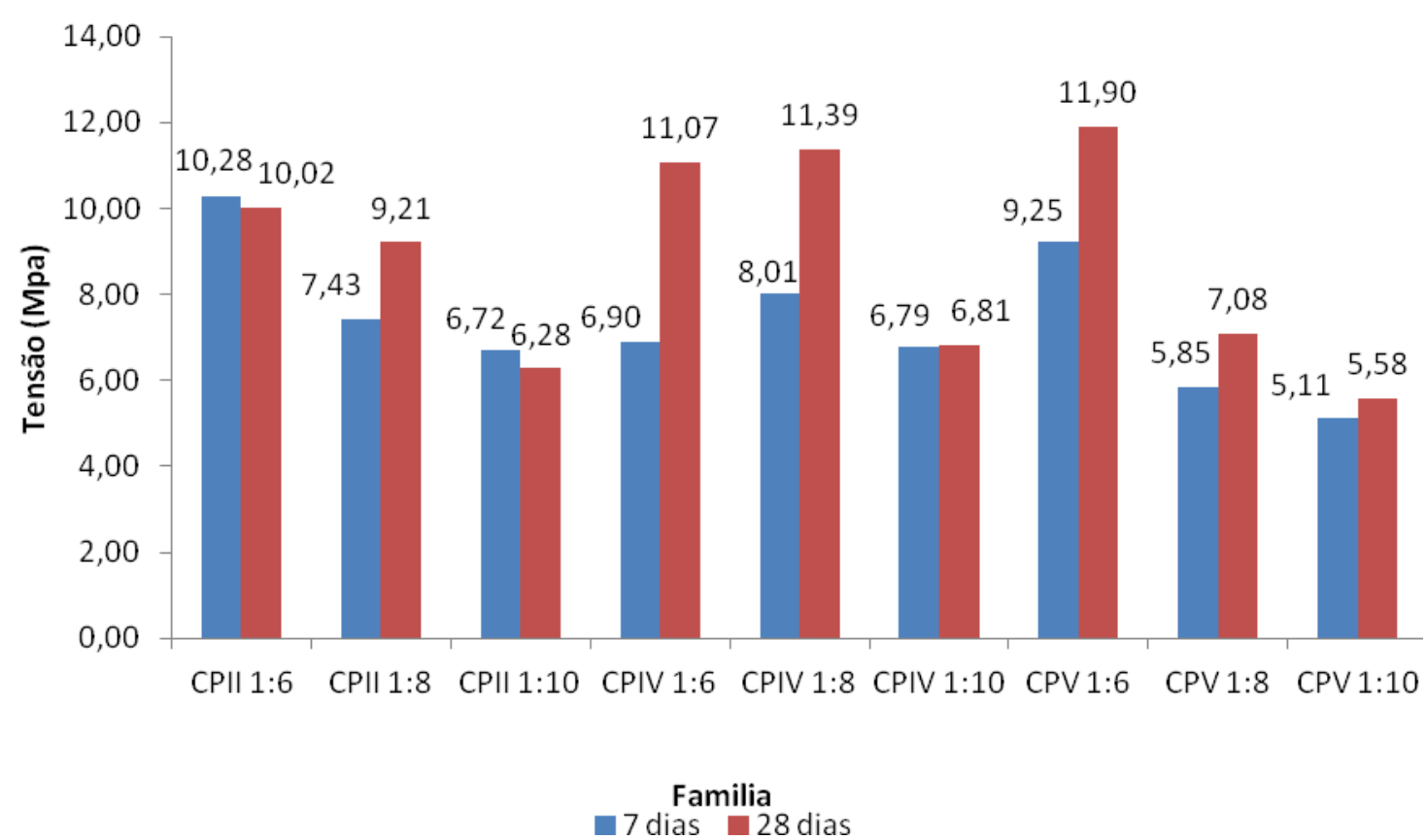

FIGURA 4: Resultados médios da resistência à compressão na dosagem em ambiente de fábrica. FONTE: Autoria Própria.

Ao realizar-se o mesmo estudo para os concretos produzidos com o cimento CPIV 32, notase que a tendência de crescimento das resistências das famílias $1: 6$ e 1:8 foram muito semelhantes. Também aos 28 dias, encontrou-se uma diferença da ordem de $2,88 \%$, pois a família que atingiu maior resistência foi a 1:8 com 11,39 $\mathrm{MPa}$, enquanto a família 1:6 atingiu valor médio de 11,07 $\mathrm{MPa}$, ou seja, uma diferença de 0,32 MPa. É importante ressaltar que a família 1:6, deste cimento, foi a primeira a ser produzida na fábrica no dia da dosagem. Esse fator, de acordo com os estudos de Frasson (2000), interfere significativamente nos resultados, pois as máquinas ainda não estão com seu desempenho de $100 \%$, que atingem depois da realização do primeiro ciclo, pois desta maneira os maquinários estão em pleno funcionamento.

O cimento CPV ARI foi o que apresentou o traço com maior resistência aos 28 dias para os blocos de concreto, sendo a mesma atingida pela família 1:6, com 11,90 MPa. Também, foi o que apresentou maior diferença para as outras famílias, sendo $40,48 \%$ superior à família $1: 8$ e $113,37 \%$ para 1:10.

A NBR 6136 (ABNT, 2014) especifica que blocos da classe $A$, com função estrutural e podendo, também, ser utilizado abaixo do nível do solo, tenham fbk $\geq 8 \mathrm{MPa}$. Para realizar esta verificação foi aplicada a equação 1 , já apresentada, em cada família de traço. A Tabela 3 apresenta o resultado do cálculo do fbk para cada família e a condição de verificação.

As famílias que não atingiram a condição foram as 1:6 e 1:10 do cimento CPV ARI. Porém, a família 1:6 teve uma diferença de 0,01 MPa e a família 1:10 de 0,03 MPa. Apesar da pouca diferença para atingir a condição, a NBR 6136 (ABNT, 2014) ainda determina que blocos da classe $B$ também podem ter função estrutural, entretanto, devem ser usados acima do nível do solo, mas com $4 \leq \mathrm{fbk}<8$ $\mathrm{MPa}$. Portanto, se forem avaliados os limites permitidos para blocos estruturais, todas as famílias ensaiadas podem ser consideradas verificadas quanto a condição de resistência à compressão estabelecida pela norma.

Ao analisar-se os valores médios das famílias e utilizando, portanto, ambas as classes A e $B$, todas as famílias seriam consideradas aptas a exercer função estrutural, pois todos os resultados médios de resistência característica à compressão foram superiores a $4 \mathrm{MPa}$. 
TABELA 3: Resultados fbk de cada família.

\begin{tabular}{cccc} 
Família & $\mathbf{f}_{b k}$ & $\mathbf{f}_{b k}>0,89 f_{(1)}$ & Condição \\
\hline CPII 1:6 & 8,56 & 7,97 & OK \\
\hline CPII 1:8 & 7,82 & 7,30 & OK \\
\hline CPII 1:10 & 4,71 & 4,55 & OK \\
\hline CPIV 1:6 & 9,70 & 8,99 & OK \\
\hline CPIV 1:8 & 9,44 & 8,88 & OK \\
\hline CPIV 1:10 & 6,03 & 5,44 & OK \\
\hline CPV 1:6 & 8,46 & 8,47 & NÃO \\
\hline CPV 1:8 & 5,32 & 4,97 & OK \\
\hline CPV 1:10 & 4,35 & 4,38 & NÃO
\end{tabular}

FONTE: Autoria Própria.

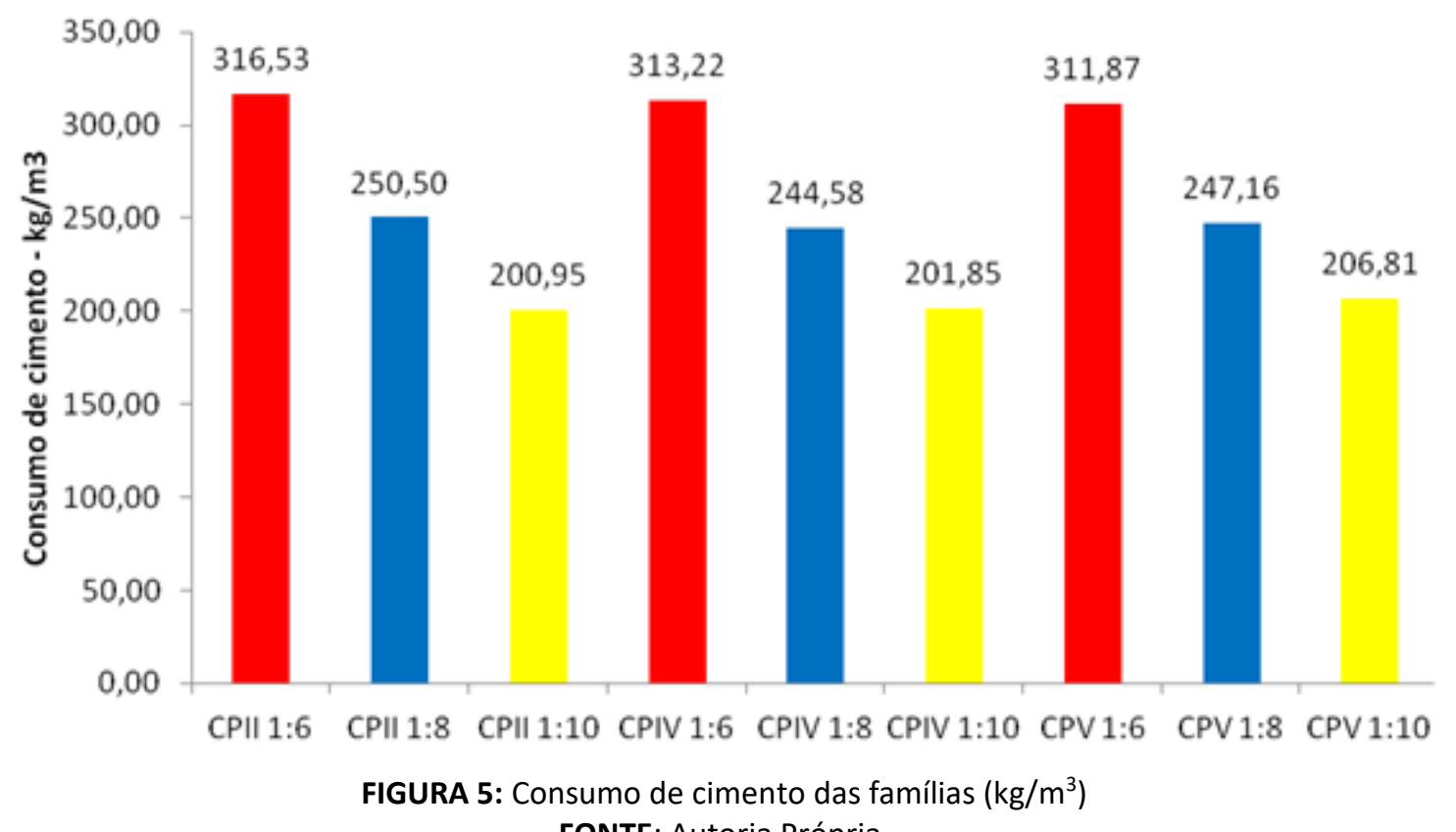

FONTE: Autoria Própria.

Outro fator importante é o consumo de cimento que cada família obteve. A partir da massa específica dos materiais e do traço unitário, foi possível determinar o consumo de cimento de cada traço, conforme a Figura 5.

As famílias 1:6 apresentaram consumo mínimo de cimento de aproximadamente 311 $\mathrm{kg} / \mathrm{m} 3$, com consumo médio de aproximadamente $314 \mathrm{~kg} / \mathrm{m} 3$ enquanto as famílias 1:8 apresentaram, em média, consumo de $247 \mathrm{~kg} / \mathrm{m} 3$. Constata-se, desta maneira, que ao comparar-se as famílias 1:6 e
1:8 houve uma redução entorno de $21 \%$ no consumo de cimento.

\section{CONCLUSÕES}

Portanto, em função dos blocos produzidos com concretos de traços 1:6 possuírem um maior consumo de cimento, tendo assim maior custo que os traços 1:8, e que os traços 1:8 atingiram o mínimo de resistência estrutural (CPII F 32 = 9,21MPa; CPIV $32=11,39 \mathrm{MPa} ;$ CPV ARI = 
$7,08 \mathrm{MPa}$ ), determinada pela norma, conclui-se que o traço 1:8 é adequado para uso estrutural e mais econômico.

A avaliação entre cimentos permite concluir que os comportamentos mecânicos foram semelhantes, porém o CPII F 32 é um cimento com maior dificuldade de aquisição e o CPVARI tem uma maior tradição de uso em fábricas de elementos pré-moldados. Também, se ressalva que o CPIV proporcionou um material com visual final com melhor acabamento que os outros dois cimentos.

\section{AGRADECIMENTOS}

Agradecimento a CAPES/CNPQ pela disponibilidade da bolsa e ao laboratório da Engenharia Civil da UFPel pela utilização do espaço para realização dos ensaios.

\section{REFERÊNCIAS BIBLIOGRÁFICAS}

ASSOCIAÇÃO BRASILEIRA DE NORMAS TÉCNICAS. Bloco vazado de concreto simples para alvenaria estrutura Método de ensaio: Análise dimensional e determinação da absorção de água, da resistência à compressão e da retração por secagem. NBR 12118. Rio de Janeiro, 2014.

ASSOCIAÇÃO BRASILEIRA DE NORMAS TÉCNICAS. Bloco vazado de concreto simples para alvenaria estrutural Requisitos. NBR 6136. Rio de Janeiro, 2014.

BALDAUF, Alexandra Staudt Follmann. Contribuição à Implementação da Coordenação Modular da Construção no Brasil. 2004. 148 p. Dissertação (Mestrado em Engenharia Civil) - Programa de Pós-Graduação em Engenharia Civil, Universidade Federal do Rio Grande do Sul, Porto Alegre, 2004.

BARBOSA, C. S. Resistência e deformalidade de blocos vazados de concreto e suas correlações com as propriedades mecânicas do material constituinte. Dissertação (Mestrado em Engenharia) - Escola de Engenharia de São Carlos, Universidade de São Paulo, São Carlos, 2004.

BEZERRA, Augusto Cesar da Silva. Influência das variáveis de ensaio nos resultados de resistência à compressão de concretos: Uma análise experimental e computacional. 2007. Dissertação (Mestrado) Universidade Federal de Minas Gerais, Escola de Engenharia. 2007.

DRYSDALE, R. G.; HAMID, A. A.; BAKER, L. R. Mansory Structures - Behavior and Design. 2. Ed. Englewood Cliffs, New Jersey: Prentice Hall. 888 p. 2012.
FERNANDES, Idário. Blocos e Pavers - Produção e controle de qualidade. 6a edição. 2015, 200 pag. Ed Treino Assessoria e Treinamentos Empresarias Ltda. 2015.

FERREIRA JUNIOR, S. Produção de blocos de concreto para alvenaria - Prática recomendada. Boletim Técnico 103. São Paulo, São Paulo, 1995.

FORTES, Ernesto Silva. Influência do capeamento e caracterização da resistência a compressão de alvenaria estrutural de blocos de concreto. 2012, $303 \mathrm{f}$. Dissertação (Mestrado) - Universidade Federal de São Paulo, São Paulo, 2012.

FRANCO, L.S. Aplicação de diretrizes de racionalização construtiva para a evolução tecnológica dos processos construtivos em alvenaria estrutural não armada. São Paulo: USP, 1992. 319p. Tese (Doutorado em Engenharia Civil) - Escola Politécnica da Universidade de São Paulo, 1992.

FRASSON JUNIOR, A. Metodologia de dosagem e processo produtivo de blocos de concreto para alvenaria estrutural. Dissertação (Mestrado em Engenharia), Universidade Federal de Santa Catarina, Florianópolis, Santa Catarina, 2000.

FRASSON JÚNIOR, A.; OLIVEIRA, A. L.; PRUDÊNCIO JÚNIOR, L. R.. Metodologia de dosagem para blocos de concreto empregados em alvenaria estrutural - Parte 1. Caderno técnico alvenaria estrutural, v. 25 , p. 31-38, 2008.

HENDRY, A.W. Engineered design of masonry buildings: fifty years development in Europe. Prog. Struct. Eng. Mater. 2002; 4:291-300. University of Edinburgh, Scotland.

IZQUIERDO, O. S. Influência do tipo de argamassamento e da utilização de peças de ajuste dimensional na resistência à compressão da alvenaria de blocos de concreto. São Carlos, 2011. 179p. Dissertação (Mestrado) em Engenharia de Estruturas - Escola de Engenharia de São Carlos da Universidade de São Paulo. 2011.

MAURÍCIO, R. M.; CAMACHO, J. S.; ANDOLFATO, R. P. Resistência à compressão axial de blocos de concreto capeados com diferentes materiais. In: CONGRESSO BRASILEIRO DO CONCRETO, 46. 2004, Florianópolis. Anais... Florianópolis: IBRACON, 2004. v.6, p. 1271-1280. 2004.

MEDEIROS, J. S. Alvenaria estrutural não armada de blocos de concreto: produção de componentes e parâmetros de projeto. Dissertação (Mestrado), São Paulo, São Paulo, 1993.

MEDEIROS, J. S.; DORNELLES, V.P.; FRANCO, L. S. Blocos de concreto para a alvenaria estrutural: avaliação de parâmetros básicos de produção. Florianópolis, Santa Catarina, 1994. 
OSAMA A. A.; AMEED, A. S. The Effect of Campping Condition on the Compressive Strength of Concrete Hollow Blocks. Na-Najah Universidade J. Res. (N. Sc), Vol. 17(1), 2003.

PRUDÊNCIO JR, L. R. Resistência à Compressão da Alvenaria e Correlação entre a Resistência de Unidades, Prismas e Paredes Mestrado em Engenharia. 1986. Dissertação (Mestrado em Construção Civil). Universidade Federal do Rio Grande do Sul, UFRGS, Brasil. 1986.

PRUDÊNCIO JR, L. R; OLIVEIRA, A. L; FRASSON JUNIOR, A. Metodologia de dosagem para blocos concreto empregados em alvenaria estrutural. Santa Catarina, 2000.

RAMALHO, M.; CORREA, M. R. S. Projetos de edifícios de alvenaria estrutural. São Paulo: Pini, 2003.

RODRIGUES, P. P. F. Parâmetros de dosagem do Concreto. São Paulo, São Paulo,1995.

ROMAN, Humberto Ramos et al. Manual de Análise de Alvenaria Estrutural da Caixa Econômica Federal. Florianópolis: NPC (Núcleo de Pesquisa em Construção Universidade Federal de Santa Catarina); GDA (Grupo de Desenvolvimento de Sistemas de Alvenaria Universidade Federal de Santa Catarina) e FEESC (Fundação de Ensino de Engenharia em Santa Catarina), 2004.

SOTO IZQUIERDO, I. Uso de fibra natural de sisal em blocos de concreto para alvenaria estrutural. Dissertação (Mestrado em estruturas). Escola de Engenharia de São Carlos da Universidade de São Paulo, 2011.

TANGO, C. E. S. Blocos de concreto: dosagem, produção e controle

de

qualidade. Instituto de Pesquisas Tecnológicas - IPT, São Paulo, São Paulo, 1984.

ZECHMEISTER, Dóris. Estudo para a padronização das dimensões de unidades de alvenaria estrutural no Brasil através do uso da coordenação modular. Dissertação (Mestrado em Engenharia Civil). Universidade Federal do Rio Grande do Sul, UFRGS, Brasil. 2005. 